\title{
Effects of High Hydrostatic Pressure Processing on the Number of Bacteria and Texture of Beef Liver
}

\author{
Hirokazu Ogihara, ${ }^{1}$ Hodaka Suzuki, ${ }^{2,3}$ Masaki Michishita, ${ }^{4}$ \\ Hitoshi Hatakeyama, ${ }^{4}$ and Yumiko Okada ${ }^{3}$ \\ ${ }^{1}$ College of Bioresource Sciences, Nihon University, 1866 Kameino, Fujisawa-shi, Kanagawa 252-0880, Japan \\ ${ }^{2}$ College of Agriculture, Ibaraki University, 3-21-1 Chuo, Ami, Inashiki, Ibaraki 300-0393, Japan \\ ${ }^{3}$ Division of Biomedical Food Research, National Institute of Health Sciences, 1-18-1 Kamiyoga, Setagaya-ku, Tokyo 158-8501, Japan \\ ${ }^{4}$ Faculty of Veterinary Science, Nippon Veterinary and Life Science University, 1-7-1 Kyonancho, Musashino-shi, Tokyo 180-8602, Japan
}

Correspondence should be addressed to Hodaka Suzuki; hodaka@nihs.go.jp

Received 1 February 2017; Accepted 24 April 2017; Published 14 May 2017

Academic Editor: Dike O. Ukuku

Copyright ( 2017 Hirokazu Ogihara et al. This is an open access article distributed under the Creative Commons Attribution License, which permits unrestricted use, distribution, and reproduction in any medium, provided the original work is properly cited.

\begin{abstract}
Providing beef liver for raw consumption was banned in Japan on July 1, 2012. To lift the ban, the establishment of effective countermeasures for safe raw consumption is necessary. In this study, we examined the effects of high hydrostatic pressure processing on raw beef liver. Beef liver samples subjected to $300 \mathrm{MPa}$ of pressure or higher for $10 \mathrm{~min}$ at $25^{\circ} \mathrm{C}$ became firmer and showed a paler color and were considered unsuitable for raw consumption. More than 3.0 log reductions of bacteria were seen after treatments at 400 and $500 \mathrm{MPa}$, but the treatment with lower pressure did not show enough microcidal effects for safe consumption. Histological and ultrastructural analysis revealed that high hydrostatic pressure processing increased mitochondrial swelling and reduced rough endoplasmic reticula in hepatocytes, and such changes might be related to the observed changes of texture in the treated raw beef liver.
\end{abstract}

\section{Introduction}

Raw meat dishes, such as "steak tartare," "mett," and "yukhoe," are consumed in many countries, in Europe and Asia. In Japan, raw beef meat and liver, called "Gyu-sashi" and "Reba-sashi," have/had sometimes been consumed. However, triggered by an outbreak of enterohemorrhagic Escherichia coli that occurred on April and May 2011, the Ministry of Health, Labour and Welfare of Japan set a new standard for preparing raw beef on October, 2011. The Ministry imposed a ban on serving raw beef liver at restaurants and meat shops in July, 2012, which will remain in effect until effective countermeasures for safe raw consumption are established [1]. Nevertheless, some people in Japan want the ban lifted to have access to raw beef liver dishes.

Animal offal can be highly contaminated with pathogens, such as enterohemorrhagic E. coli, Campylobacter spp., and Salmonella spp. [2-6]. In fact, many cases of food poisoning have been associated with meat and/or offal consumption [7-10]. For safe consumption, meat and offal are usually cooked with heat. Heat cooking is quite effective in killing pathogens, but it changes the taste, aroma, and texture of foods. Therefore, alternative processing methods are needed to kill pathogens with minimum changes to taste, aroma, and texture, and thereby allow safe consumption of raw meat and offal.

Radiation [11, 12], high-voltage pulse [13], light pulse [14], high pressure [15], ozone [16], and other methods are known to be effective nonheat sterilization procedures. In particular, high hydrostatic pressure (HHP) processing may be potentially an effective method for reducing the risk of raw beef liver without changing taste, aroma, or texture $[17,18]$. So far, a single report describing the effects of high pressure processing on the number of pathogenic bacteria in livestock offal has been found in the literature [19].

In this study, we aimed to examine the effects of HHP processing on bacterial reduction and histological changes in raw beef liver. 


\section{Materials and Methods}

2.1. Preparation of Bacteria. A nonpathogenic E. coli strain, ATCC25922, was used instead of enterohemorrhagic $E$. coli O157:H7. The strain was kept at $-80^{\circ} \mathrm{C}$ until use and passaged twice in Trypticase Soy broth (Becton Dickenson and Company, Franklin Lakes, NJ, USA) at $37^{\circ} \mathrm{C}$ before experiments. The culture was centrifuged at $8,000 \mathrm{rpm}$ for $10 \mathrm{~min}$. Cell pellets were washed and resuspended in sterilized phosphate buffered saline (PBS, $\mathrm{pH}$ 7.0). Bacterial cell density was adjusted to $1 \times 10^{8}$ or $1 \times 10^{9}$ colony forming units $(\mathrm{CFU}) / \mathrm{mL}$.

2.2. Preparation of Beef Liver Samples. Beef liver, which was taken on the previous day and stored under refrigeration, was purchased from Tokyo Shibaura Zouki Co., Ltd. (Tokyo, Japan), a meat broker company. The beef liver was transferred under cold conditions (using refrigerants) to the laboratory and used on the same day. The beef liver was cut into pieces of approximately $2 \mathrm{~cm} \times 3 \mathrm{~cm} \times 0.5 \mathrm{~cm}$, weighing approximately $10 \mathrm{~g}$. The samples were vacuum-packed in plastic bags twice and sealed using a heat sealer. To evaluate the microcidal effects of HHP treatment, $10 \mu \mathrm{L}$ of $E$. coli suspension (in PBS), $1 \times 10^{8} \mathrm{CFU} / \mathrm{mL}$, was injected in the sample at each of 10 regularly spaced points using micropipette with sterilized pipette tips before being packed.

2.3. HHP Treatment. Beef liver samples in plastic bags were pressurized with a water-based prototype pressurization apparatus (HPV-80C20-S; Sugino Machine Ltd., Toyama, Japan). Pressurization reached $200 \mathrm{MPa}$ after approximately $60 \mathrm{sec}$, and decompression took approximately $10 \mathrm{sec}$. The initial temperature before HHP treatment was always at $25^{\circ} \mathrm{C}$; however, the temperature during HHP treatment was not monitored.

2.4. Bacteria Counting after HHP Treatment. The number of E. coli in PBS after HHP treatment was determined by the pour culture method in Trypticase Soy agar (TSA, Becton Dickenson and Company). The number of E. coli in beef liver after HHP treatment was determined using TSA and chromogenic XM-G agar (Nissui Pharmaceutical Co., Ltd., Tokyo, Japan), a selective agar for coliforms and E. coli. After incubation at $37^{\circ} \mathrm{C}$ for $24 \mathrm{hr}$, typical colonies with blue color on XM-G agar were identified as presumptive E. coli. The number of bacteria in each sample was calculated from the number of colonies multiplied by the dilution factor.

\subsection{Experimental Designs}

2.5.1. Effects of HHP Treatment on E. coli in PBS. Five milliliters of polypropylene tubes (Greiner Bio-One, Kremsmünster, Austria) was filled with E. coli suspension in PBS $\left(1 \times 10^{9} \mathrm{CFU} / \mathrm{mL}\right)$ and subjected to HHP at 200, 300, 400 , and $500 \mathrm{MPa}$. The treatment was performed for 10,20 , and $30 \mathrm{~min}$ at each pressure at $25^{\circ} \mathrm{C}$. The bacterial suspension after HHP treatment was serially diluted with sterilized saline supplemented with $0.1 \%$ peptone and inoculated on

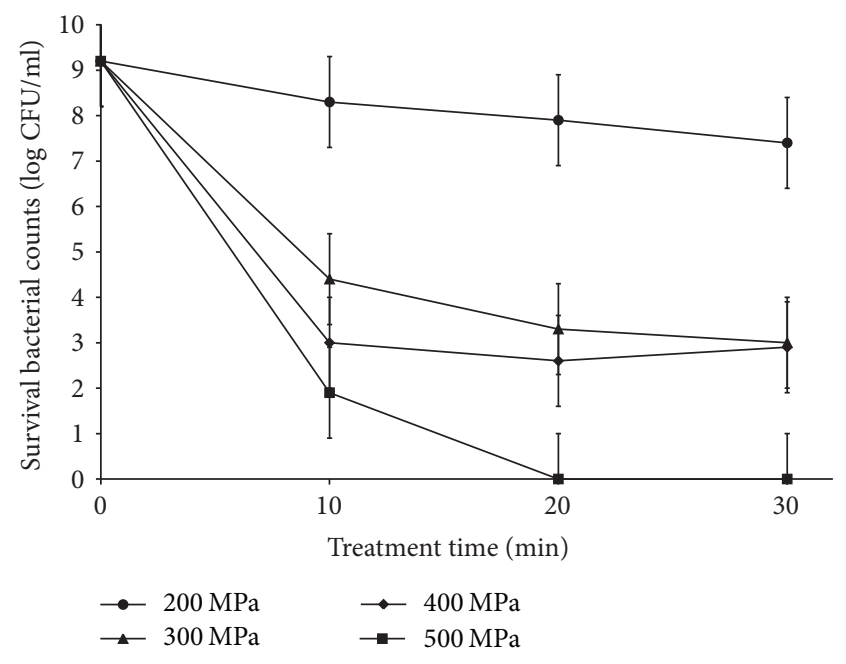

FIgURE 1: Effects of HHP treatment on E. coli in PBS.

TSA plates. The limit of detection for this experiment was $1 \mathrm{CFU} / \mathrm{mL}$. The experiments were repeated 3 times.

2.5.2. Effects of HHP Treatment on E. coli Inoculated in Liver Samples. Liver samples inoculated with $E$. coli in plastic bags were submitted to HHP at 200, 300, 400, and $500 \mathrm{MPa}$ for $10 \mathrm{~min}$ at $25^{\circ} \mathrm{C}$. For $E$. coli colony counting, $10 \mathrm{~g}$ of liver sample was homogenized in $90 \mathrm{~mL}$ of PBS for 2 min using a Stomacher ${ }^{\circledR} 400 \mathrm{~T}$ circulator (Seward Ltd., West Sussex, UK), serially diluted in PBS, and inoculated on TSA and XM-G agar plates. The limit of detection for this experiment was $10 \mathrm{CFU} / \mathrm{g}$. The experiments were repeated 3 times.

2.5.3. Effects of HHP Treatment on Color, Histology, and Ultrastructure of Liver Samples. Liver samples treated at 200, 300,400 , and $500 \mathrm{MPa}$ for $10 \mathrm{~min}$ at $25^{\circ} \mathrm{C}$ were observed macroscopically and then cut into slices. The colors of the samples were measured by colorimeter (CR-200, Minolta Co., Ltd., Osaka, Japan). Results are expressed as a combination of the values of $L^{*}, a^{*}$, and $b^{*}: L^{*}$ represents a gradation from light to dark; $a^{*}$, red to green; and $b^{*}$, yellow to blue.

For light microscopy analysis, samples were fixed in $10 \%$ neutral buffered formalin and embedded in paraffin. Thin sections $(4 \mu \mathrm{m})$ were stained with hematoxylin and eosin (HE).

For electron microscopy analysis, small pieces of liver samples were prefixed in MacDowell's and Trump's 4F:1G fixative [20] and postfixed in 1\% osmium tetraoxide, followed by $0.2 \mathrm{M}$ phosphate buffer, and then embedded in epoxy resin. Using an electron microscope (JEM1011; JEOL Ltd., Tokyo, Japan), ultrathin sections were examined after staining with uranyl acetate and lead citrate.

\section{Results}

3.1. Effects of HHP Treatment on E. coli in PBS. The number of E. coli in PBS before HHP treatment was $9.0 \log \mathrm{CFU} / \mathrm{mL}$ (Figure 1). No significant change was found in the number 
TABLE 1: Colorimetric values of liver samples before and after HHP treatment.

\begin{tabular}{lccc}
\hline Treatment & $L^{*}$ & $a^{*}$ & $b^{*}$ \\
\hline $0.1 \mathrm{Mpa}$ & $36.7 \pm 1.3$ & $6.5 \pm 0.6$ & $2.2 \pm 0.3$ \\
$200 \mathrm{MPa}$ & $38.1 \pm 1.4$ & $6.7 \pm 0.5$ & $0.5 \pm 0.4$ \\
$300 \mathrm{MPa}$ & $44.3 \pm 1.1^{\dagger \dagger}$ & $10.1 \pm 1.0^{\dagger \dagger}$ & $2.2 \pm 1.4$ \\
$400 \mathrm{MPa}$ & $47.7 \pm 1.9^{\dagger \dagger}$ & $10.9 \pm 0.4^{\dagger \dagger}$ & $6.2 \pm 0.7^{\dagger \dagger}$ \\
$500 \mathrm{MPa}$ & $50.4 \pm 0.4^{\dagger \dagger}$ & $10.1 \pm 0.2^{\dagger \dagger}$ & $8.0 \pm 0.6^{\dagger \dagger}$ \\
\hline
\end{tabular}

${ }^{\dagger \dagger} p<0.01$.

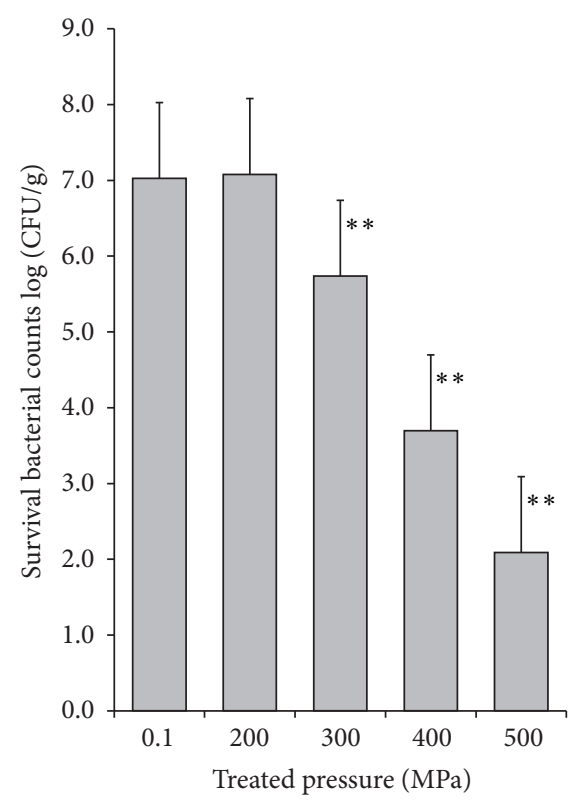

(a)

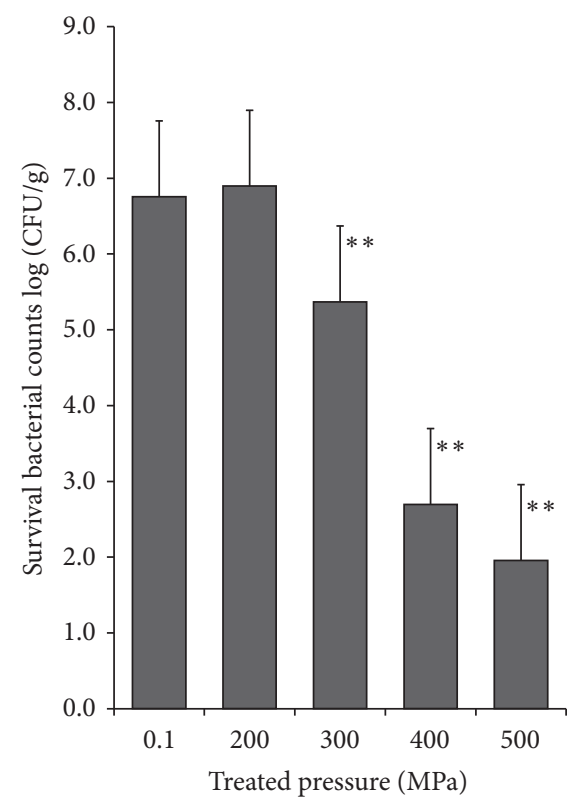

(b)

FIGURE 2: (a) The number of $E$. coli in the liver samples treated with high pressure measured (TSA plates). ${ }^{* *} p<0.01$ compared with nontreated samples (expressed as $0.1 \mathrm{MPa}$, because of the atmospheric pressure). (b) The number of $E$. coli in the liver samples treated with high pressure measured (XM-G agar plates). ${ }^{* *} p<0.01$ compared with nontreated samples (expressed as $0.1 \mathrm{MPa}$, because of the atmospheric pressure).

of E. coli after HHP treatment at $200 \mathrm{MPa}$ for $10 \mathrm{~min}$, but a slight decrease was observed after $20 \mathrm{~min}$ and a decrease of 1.0 log in cell number was seen after $30 \mathrm{~min}$ HHP treatment. Treatments at higher pressures and longer periods led to more rapid and significant decreases in the number of $E$. coli. Treatment at $500 \mathrm{MPa}$ for $10 \mathrm{~min}$ led to a decrease in the number of E. coli to $2.5 \log \mathrm{CFU} / \mathrm{mL}$, and after 20 or $30 \mathrm{~min}$ the number of viable cells was below the detection limit (1 CFU/mL).

3.2. Effects of HHP Treatment on E. coli Inoculated in Liver Samples. Figures 2(a) and 2(b) show the number of E. coli in the liver samples treated with high pressure counted on TSA and XM-G agar plates, respectively. Nontreated liver samples were expressed as $0.1 \mathrm{MPa}$ in the figures, because of the atmospheric pressure. The number of bacteria spontaneously contaminated in the liver was $5.4 \pm 0.7 \times 10^{3} \mathrm{CFU} / \mathrm{g}$ as viable aerobic bacteria on TSA agar plates, $7.0 \pm 3.0 \times 10^{1} \mathrm{CFU} / \mathrm{g}$ as coliform (red colony), and $6.3 \pm 4.5 \times 10^{1} \mathrm{CFU} / \mathrm{g}$ as $\mathrm{E}$. coli (blue colony) on XM-G agar plates, respectively. The number of $E$. coli in nontreated (E. coli inoculated) liver sample was approximately $7.0 \log \mathrm{CFU} / \mathrm{g}$. After treatment at $200 \mathrm{MPa}$, no significant change was observed in the number of $E$. coli. In contrast, a reduction of $1.5,3.0$, and $5.0 \mathrm{log} \mathrm{CFU} / \mathrm{g}$ was found at 300,400 , and $500 \mathrm{MPa}$, respectively.

3.3. Effects of HHP Treatment on Color, Histology, and Ultrastructure of Liver Samples. Liver samples in plastic bags after HHP treatment are shown in Figure 3(a); cut surfaces are shown in Figure 3(b). Liver sample volumes did not change after high pressure treatment compared with nontreated samples. The color of liver samples became paler, from reddish brown to whitish brown, under high pressure treatment. Colorimetric results of liver samples are shown in Table 1. The color of liver samples treated with high pressure showed higher $L^{*}, a^{*}$, and $b^{*}$ values. In addition, 


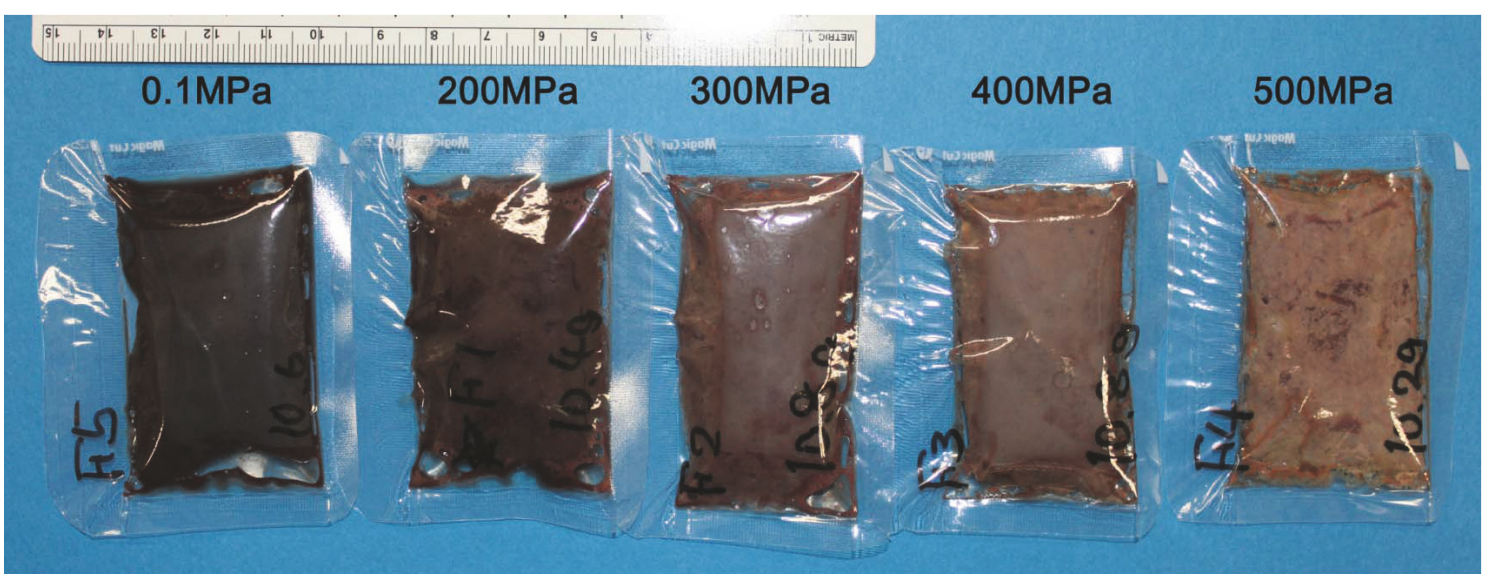

(a)

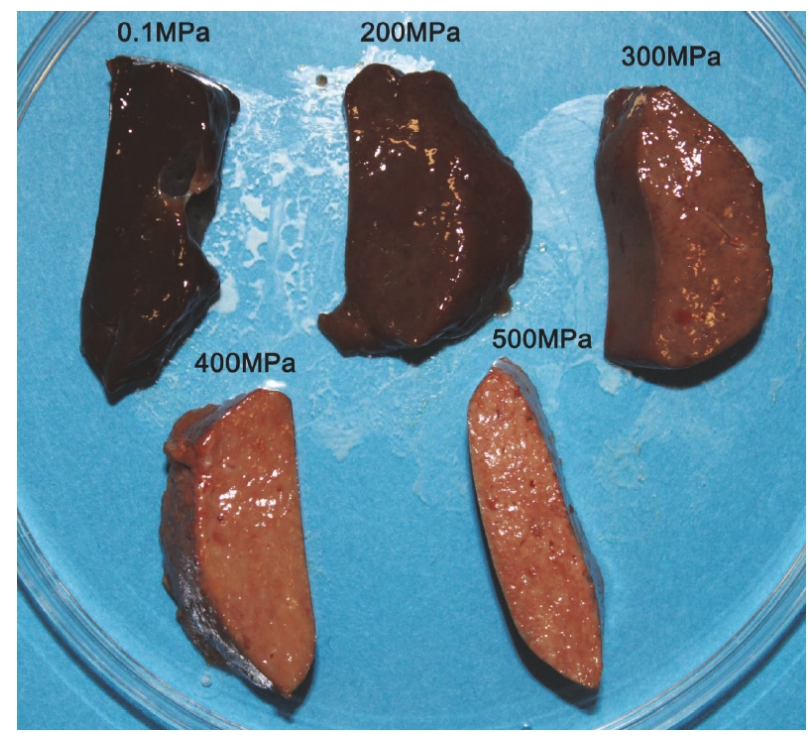

(b)

Figure 3: (a) Liver samples after HHP treatment. (b) Cut surfaces of liver after HHP treatment.

liver samples submitted to high pressure showed a firmer consistency when cutting. Nontreated liver samples were expressed as $0.1 \mathrm{MPa}$ in the figures and the table, because of the atmospheric pressure.

Histological analysis showed no obvious changes in lobular structures and funicular arrangements of liver cells treated with high pressure (Figure 4(a)) when compared to nontreated samples. However, hepatocytes showed a faintly eosinophilic cytoplasm containing diffusely eosinophilic granules that increased in a pressure-dependent manner (Figure 4(b)). Small eosinophilic particles were also observed in blood vessels (Figure 4(b)).

Ultrastructural analysis showed swollen mitochondria containing dense amorphous granules in hepatocytes (Figure 5(a)). The size of the amorphous granules increased with high pressure treatment (Figure 5(b)), and the rough endoplasmic reticula disappeared completely (Figure 5(c)).

\section{Discussion}

The Ministry of Health, Labour and Welfare of Japan has banned providing beef liver for raw consumption and requires it to be cooked at $63^{\circ} \mathrm{C}$ for at least $30 \mathrm{~min}$, or any other heat condition (e.g., at $75^{\circ} \mathrm{C}$ for at least $1 \mathrm{~min}$ ) with proven equivalent microcidal effects [21]. However, some people in Japan have been waiting for the establishment of effective countermeasures and for the ministry to lift the ban.

In European countries such as France and Germany, raw ground meat is consumed and is considered a public health concern. Black et al. [22], Hsu et al. [23], and Jiang et al. [24] reported that high pressure processing of ground meat is potentially effective in reducing the risk of ingesting pathogenic bacteria.

Uenaka et al. [19] reported that E. coli, Salmonella spp., and Staphylococcus aureus inoculated into beef liver are killed effectively by high pressure processing (400 MPa for $10 \mathrm{~min}$ 

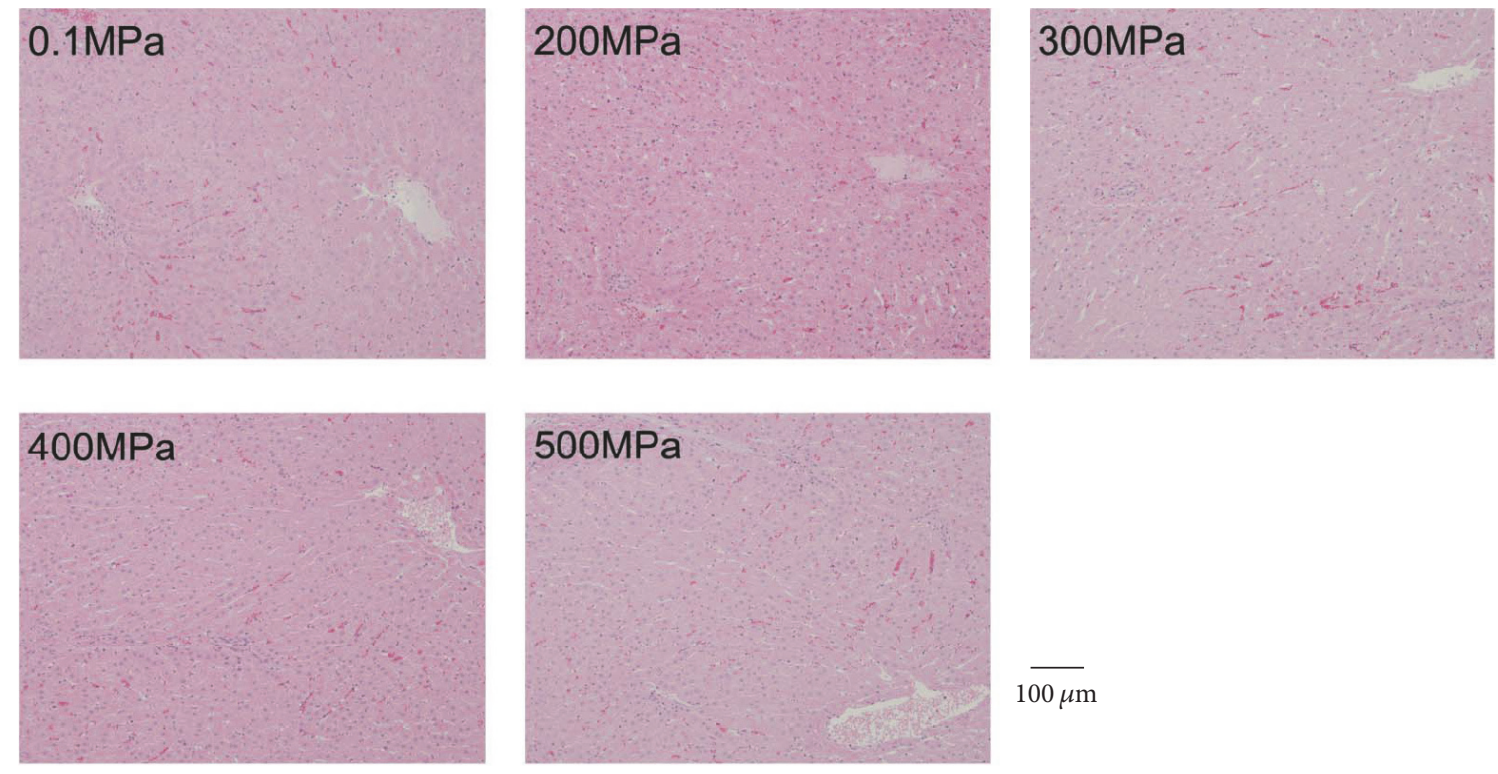

(a)
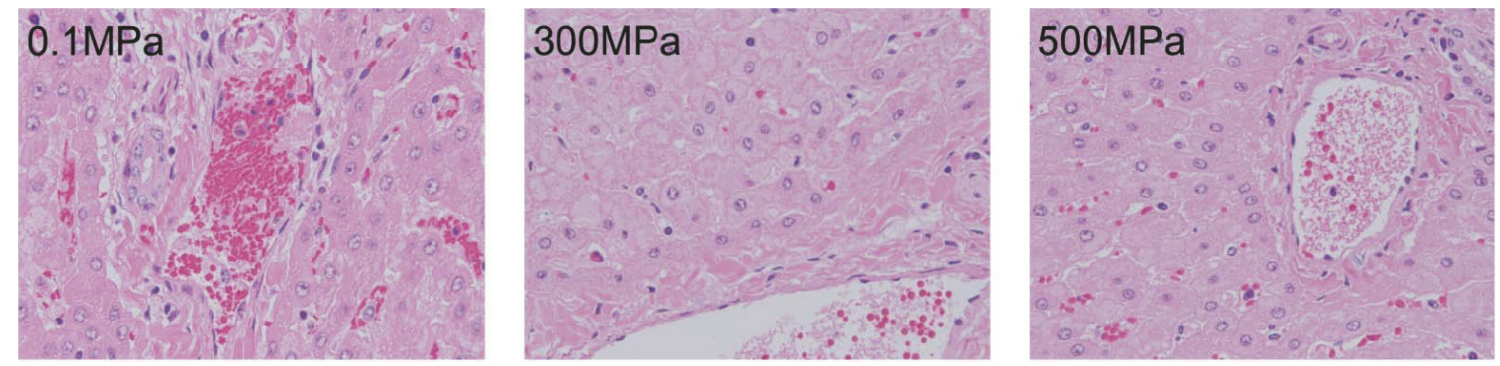

$\overline{20 \mu \mathrm{m}}$

(b)

Figure 4: (a) Histological analysis of liver after HHP treatment (low magnification). (b) Histological analysis of liver after HHP treatment (high magnification).

6 times, or $600 \mathrm{MPa}$ for $30 \mathrm{~min}$ once, at room temperature). They also reported that beef liver treated 6 times with $400 \mathrm{MPa}$ for $10 \mathrm{~min}$ at room temperature showed a paler color but its taste was similar to that of untreated beef liver as evaluated by sensory tests. In this study, liver samples treated at $300 \mathrm{MPa}$ or higher for $10 \mathrm{~min}$ also showed a paler color, and samples treated with $400 \mathrm{MPa}$ or $500 \mathrm{MPa}$ showed a firmer consistency and were not considered raw. No sensory tests were performed in this study. In future studies, the tenderness of treated liver samples will be measured using a rheometer.

Histological and ultrastructural changes of the raw beef liver by HHP treatment were first reported in this study. The changes were more severe in liver samples treated with higher pressure, both histologically and ultrastructurally. The eosinophilic granules seen dispersed in hepatocytes under light microscopy are thought to correspond to the dense amorphous granules observed in mitochondria under electron microscopy. Such changes are thought to underlie changes in texture of beef liver. The small eosinophilic particles observed in blood vessels are thought to be the debris of red blood cells. The destruction of red blood cells and less eosinophilic cytoplasm of hepatocytes may be related to the paler color of liver treated with high pressure.

We conclude that HHP treatment at $300 \mathrm{MPa}$ or higher for $10 \mathrm{~min}$ is unsuitable for raw consumption of beef liver. However, lower pressure treatment did not show enough microcidal effects for safe consumption. In future studies, combinations of shorter/longer duration, single/multiple treatment(s), and lower/higher temperature under lower pressure will be performed to find the optimal conditions to minimize health risks and keep texture of raw beef liver.

\section{Conflicts of Interest}

The authors declare that there are no conflicts of interest regarding the publication of this paper. 

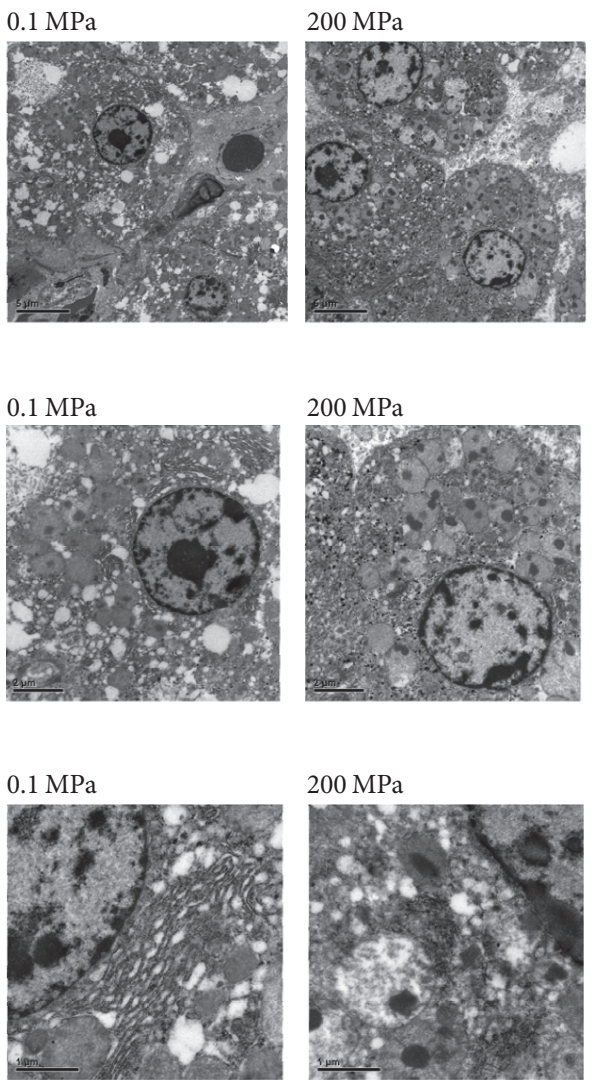

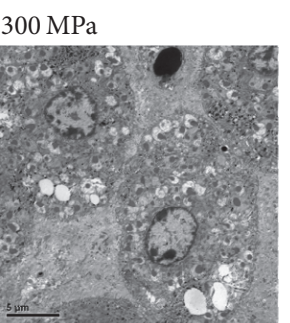

$400 \mathrm{MPa}$

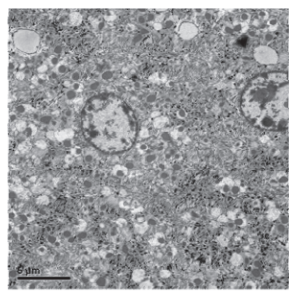

(a)

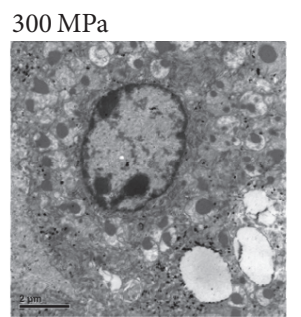

(b)

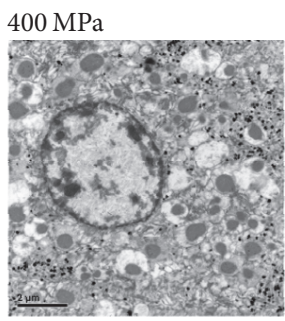

$400 \mathrm{MPa}$
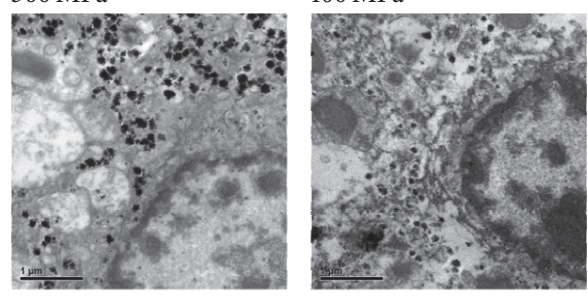

$500 \mathrm{MPa}$
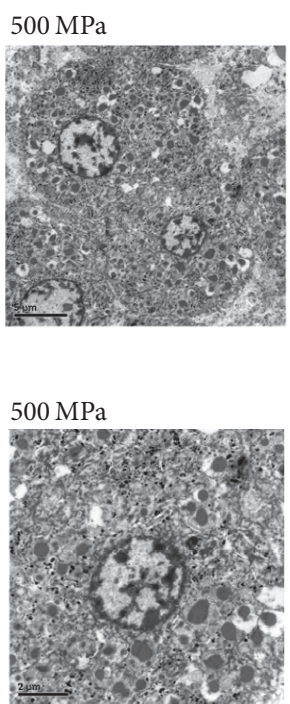

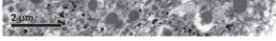

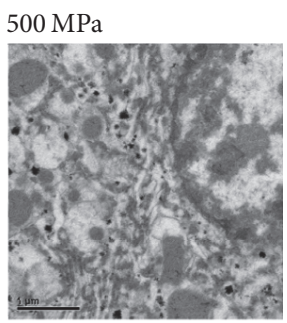

(c)

FIGURE 5: (a) Ultrastructural analysis of liver after HHP treatment (hepatocyte). (b) Ultrastructural analysis of liver after HHP treatment (mitochondria). (c) Ultrastructural analysis of liver after HHP treatment (rough endoplasmic reticulum).

\section{Acknowledgments}

This study was supported by Health and Labour Sciences Research Grants, Research on Food Safety, from the Ministry of Health, Labour and Welfare of Japan.

\section{References}

[1] H. Suzuki and Y. Okada, "Enterohemorrhagic Escherichia coli(EHEC) infection and beef consumption in Japan," in Proceedings of the 2nd AFSSA, pp. 79-82, 2015.

[2] Ministry of Health and Labour and Welfare, "Shokuchudokukinosenjittaichosa in Heisei 22 (Surveillance of Food-Poisoning Bacterial Contamination on Food in 2011). [Internet]. [cited 2016 Sept 23]. (in Japanese)," http://www.mhlw.go.jp/ topics/syokuchu/kanren/yobou/dl/110330-1b.pdf.

[3] Ministry of Health and Labour and Welfare, "Shokuchudokukinosenjittaichosa in Heisei 23 (Surveillance of Food-Poisoning Bacterial Contamination on Food in 2012). [Internet]. [cited 2016 Sept 23]. (in Japanese)," http://www.mhlw.go.jp/ topics/syokuchu/kanren/yobou/pdf/betten-h23.pdf.

[4] Ministry of Health and Labour and Welfare, "Shokuchudokukinosenjittaichosa in Heisei 24 (Surveillance of Food-Poisoning Bacterial Contamination on Food in 2012). [Internet]. [cited 2016 Sept 23]. (in Japanese)," http://www.mhlw.go.jp/ topics/bukyoku/iyaku/syoku-anzen/gyousei/dl/130329_3.pdf.
[5] H. Suzuki and S. Yamamoto, "Study on the imported U.S. beef and the occurrence of enterohemorrhagic Escherichia coli infection in Japan," Bulletin of National Institute of Health Sciences, vol. 126, pp. 58-64, 2008.

[6] H. Suzuki and S. Yamamoto, "Food-poisoning bacterial contamination on food: a comparison between European countries and Japan," Bulletin of National Institute of Health Sciences, vol. 129, pp. 118-128, 2011.

[7] Ministry of Health and Labour and Welfare, "Shokuchudokuhasseijirei in Heisei 22 (Summary on Food Poisoning Cases in 2010). [Internet]. [cited 2016 Sept 23]. (in Japanese)," http://www.mhlw.go.jp/topics/syokuchu/10hassei/xls/jirei22.xls.

[8] Ministry of Health and Labour and Welfare, "Shokuchudokuhasseijirei in Heisei 23 (Summary on Food Poisoning Cases in 2011). [Internet]. [cited 2016 Sept 23] (in Japanese)," http://www.mhlw.go.jp/file/06-Seisakujouhou-11130500-Shokuhinanzenbu/jirei23.xls.

[9] K. Shinagawa, "Shokuniku" ni yoru biseibutsushokuchudoku to sono yobou -Tokuni, shokuniku no seishoku ni yoru chokanshukketsuseidaichokin shokuchudoku wo chusin ni-," Shokuniku no kagaku, vol. 54, pp. 29-33, 2013 (Japanese).

[10] J. Terajima, S. Iyoda, H. Izumiya et al., "Current status of enterohemorrhagic Escherichia coli infections," Japanese Journal of Food Microbiology, vol. 29, no. 2, pp. 88-93, 2012.

[11] H. Ito, "Feasibility for electron-beams inactivation of microorganisms in meat products," Food Chemicals, vol. 1998, no. 6, pp. 23-27, 1998. 
[12] H. Ito, "The basis and safety of food irradiation; advantages of radiation treatment for food sanitation and storage," JAERIReview 2001-029, 2001 (Japanese).

[13] G. A. Evrendilek, Q. H. Zhang, and E. R. Richter, "Inactivation of Escherichia coli O157:H7 and Escherichia coli 8739 in apple juice by pulsed electric fields," Journal of Food Protection, vol. 62, no. 7, pp. 793-796, 1999.

[14] J. Dunn, T. Ott, and W. Clark, "Pulsed-light treatment of food and packaging," Food Technology, vol. 49, no. 9, pp. 95-98, 1995.

[15] B. H. Hite, "The effect of pressure in the preservation of milk," West Virginia Agricultural Experiment Station, vol. 58, pp. 15-35, 1899.

[16] J.-G. Kim, A. E. Yousef, and S. Dave, "Application of ozone for enhancing the microbiological safety and quality of foods: a review," Journal of Food Protection, vol. 62, no. 9, pp. 1071-1087, 1999.

[17] H. Ogihara, M. Yatuzuka, N. Horie, S. Furukawa, and M. Yamasaki, "Synergistic effect of high hydrostatic pressure treatment and food additives on the inactivation of Salmonella enteritidis," Food Control, vol. 20, no. 11, pp. 963-966, 2009.

[18] H. Ogihara, T. Hitomi, and N. Yano, "Inactivation of some foodborne pathogens and indicator bacteria by high hydrostatic pressure," Journal of the Food Hygienic Society of Japan, vol. 39, no. 6, pp. 436-439, 1998 (Japanese).

[19] T. Uenaka, T. Mori, Y. Yabuno, and K. Sumi, "Sterilization of livestock visceral meat by high pressure treatment," Nippon Shokuhin Kagaku Kogaku Kaishi, vol. 53, no. 12, pp. 651-654, 2006 (Japanese).

[20] E. M. McDowell and B. F. Trump, "Histologic fixatives suitable for diagnostic light and electron microscopy," Archives of Pathology \& Laboratory Medicine, pp. 405-414, 1976.

[21] Director of Department of Food Safety, "Pharmaceutical and Medical Safety Bureau, Ministry of Health and Welfare. 2012. Notification No.0625.1 issued by the Director of Department of Food Safety, Pharmaceutical and Medical Safety Bureau, Ministry of Health, Labour and Welfare. [Internet]. [cited 2016 Sept 23] (in Japanese)," http://www.mhlw.go.jp/seisakunitsuite/ bunya/kenkou_iryou/shokuhin/syouhisya/110720/dl/120625_01 .pdf.

[22] E. P. Black, K. A. Hirneisen, D. G. Hoover, and K. E. Kniel, "Putting the pressure on beef," Food Engineering and Ingredients, vol. 35, no. 1, pp. 35-37, 2010.

[23] H. Hsu, S. Sheen, J. Sites, J. Cassidy, B. Scullen, and C. Sommers, "Effect of High Pressure Processing on the survival of Shiga Toxin-Producing Escherichia coli (Big Six vs. O157: H7) in ground beef," Food Microbiology, vol. 48, pp. 1-7, 2015.

[24] Y. Jiang, J. A. Scheinberg, R. Senevirathne, and C. N. Cutter, "The efficacy of short and repeated high-pressure processing treatments on the reduction of non-O157: H7 shiga-toxin producing escherichia coli in ground beef patties," Meat Science, vol. 102, pp. 22-26, 2015. 

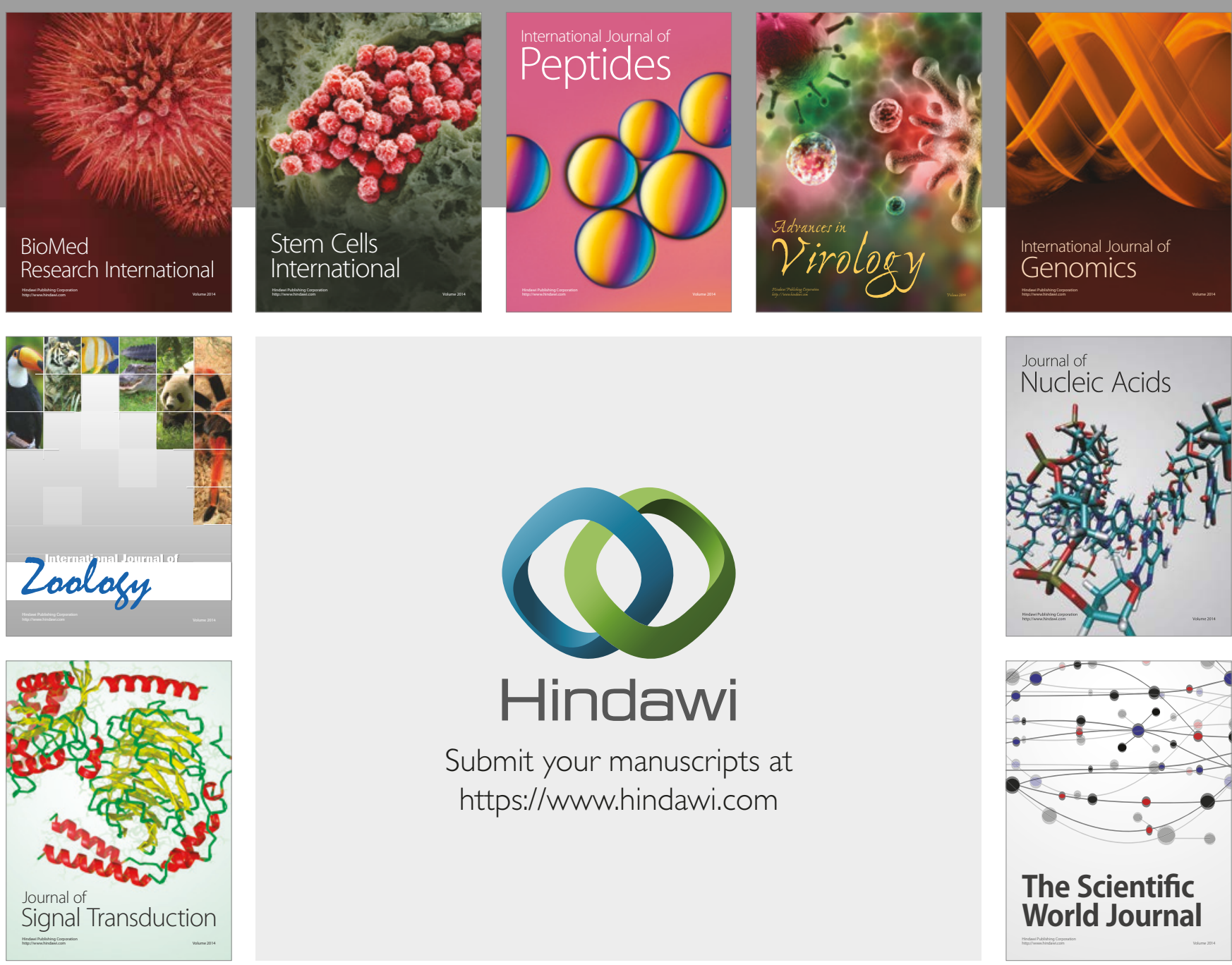

Submit your manuscripts at

https://www.hindawi.com
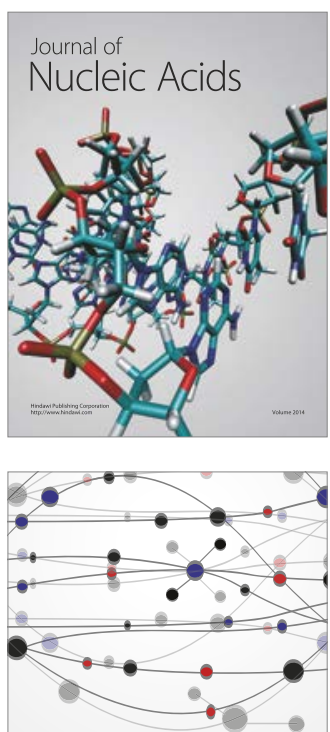

The Scientific World Journal

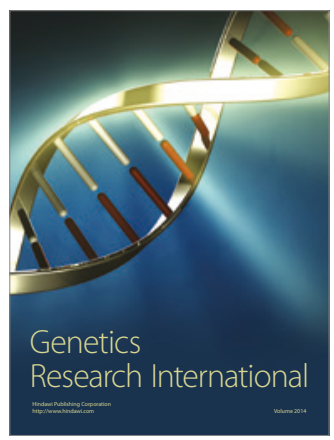

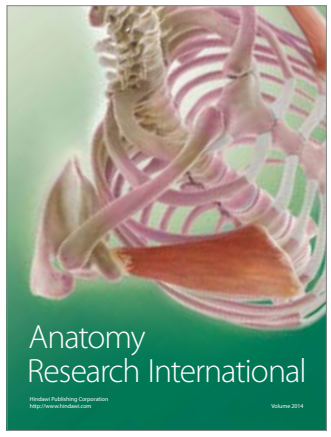

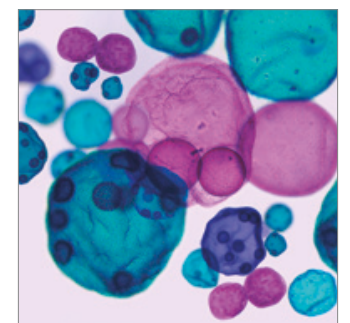

International Journal of Microbiology
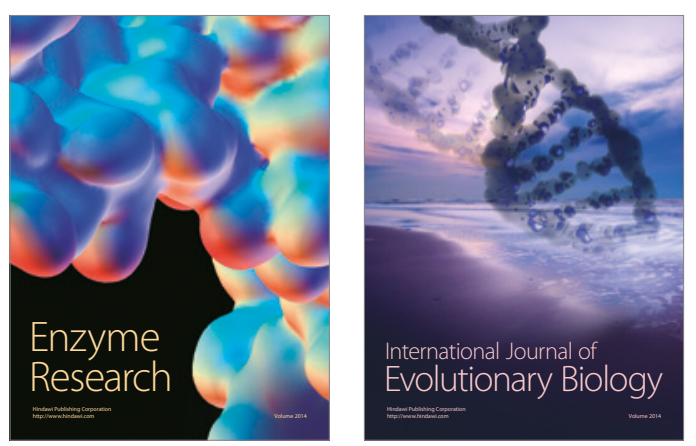
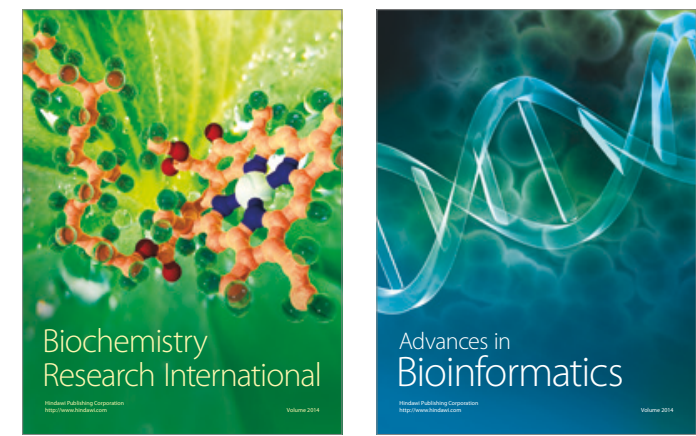

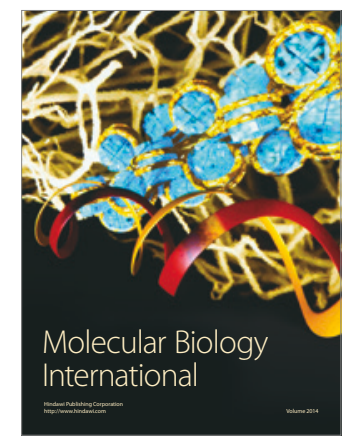

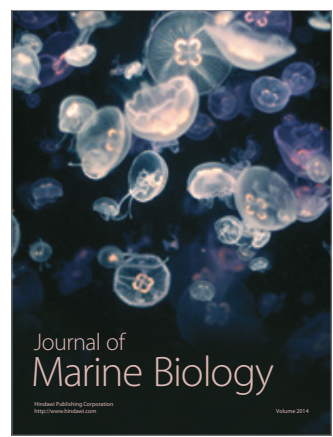

